THE INTERNATIONAL

REVIEW OF RESEARCH IN

OPEN AND DISTANCE LEARNING

\title{
Book Review - Quality Assurance and Accreditation in Distance Education and e-Learning: Models, Policies and Research
}

Editors: Insung Jung and Colin Latchem (2012)

Routledge, New York, 285 pp.

ISBN: 978-1-60752-120-4

Oally desurnet ine

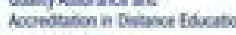

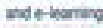

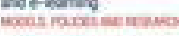

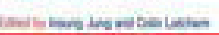

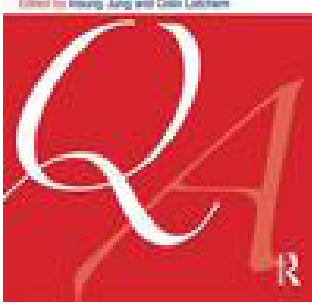

Reviewer: Kay Shattuck, Quality Matters, USA

Open and distance learning providers who have enjoyed freedom from external scrutiny may resist attempts at external regulation and auditing and look upon QA as yet another imposition of corporatization and bureaucracy on education. Others see it as a means of establishing a culture of quality, self-reflection and self-improvement.

Thus, Insung Jung and Colin Latchem, open the book for all students and practitioners of open and distance learning. Jung is a professor of Education, Media and Society at the International Christian University in Tokyo, and Colin Latchem is an Australian researcher, writer, and consultant in open and distance learning. As editors of the book they contributed a number of the 23 chapters; other chapters are provided by invited knowledgeable practitioners in various topics related to quality assurance.

Although the book is presented in chapters, I find it separates naturally into themes.

Three chapters $(1,2,3)$ provide an overview of issues that impact quality assurance and accreditation in open and distance education following the foreword from Sir John Daniel, president of the Commonwealth of Learning, and two concluding chapters (21 and 23) provide specific QA competencies and guidelines.

Ten chapters from invited authors present information on quality assurance efforts, including regional policies and guidelines: 
- Asia open and distance learning,

- Sub-Saharan Africa distance education,

- United Kingdom QA and accreditation,

- Palestine Open University,

- Australian and New Zealand distance education institutions and open education consortia policies and guidelines (two chapters),

- South Korean QM in corporate e-Learning,

- South Pacific and West Indies QA in dual-mode universities,

- North America overview of QA and accreditation,

- European QA policies and guidelines.

Six chapters focus on various educational modes:

- Models and case studies of QA in the rising number of open universities,

- Lessons learned from QA efforts in a mega-university (Indonesia Open University) and global telecentres (two chapters),

- Attempts suggested by Commonwealth of Learning's review and improvement model at lowering cost and increasing effectiveness of QA for developing countries,

- QA issues and challenges in secondary schooling for remote and socially disadvantaged communities in India and Indonesia,

- QA challenges for European small-to-medium enterprises (training).

Two chapters look at the impact of digital technologies on transforming relationships between teachers and learners and learners' perceptions of quality.

To readers who do not have a grounding in open education, I suggest, after reading the foreword and preface, begin with Latchem and Jung's chapter on "Quality Assurance and Accreditation in Open and Distance Learning" (Chapter 2); proceed to Chalmers and Johnston's chapter on "Quality Assurance and Accreditation in Higher Education" (Chapter 1); move on to Latchem and Ali's chapter on "International and Regional Quality Assurance and Accreditation" (Chapter 3); read on to Jung and Latchem's chapter on "Competencies and Quality Assurance in Distance and E-Learning" (Chapter 21); and next read Jung and Latchem's “Concluding Remarks" (Chapter 23). Then, treat yourself to the other chapters that provide rich information, including lessons learned about how well established open and distance institutions in Asia, Europe, Africa, Australia, and the Pacific address qual- 
ity assurance. Please do not be tempted to skip these chapters. To those readers who are familiar with the concept of open and distance education as a well-established mode of regionally and nationally based education openly available to citizens, I say read from cover to cover, making sure not to miss the final chapters on competencies, learners' perceptions, and concluding remarks. Then hand the book over to an e-learning manager or administrator.

Some interesting themes that run through many of the chapters include the following.

- Although distance education continues to have an image problem, as Sir Daniel pointed out, "Active QA is a necessary, if not a sufficient condition for improving its reputation, and those institutions that have engaged most intensely with QA processes, such as Open University Malaysia and the UK Open University, have derived clear benefit from doing so" (p. xiii). So QA efforts can have positive impact with shareholders.

- For-profit institutions and online technologies are playing a role in the need for open and distance education institutions to address quality assurance and the complications "enterprising" entities can create for cross-border education.

- There is discussion on whether e-learning should have specific QA criteria and accreditation or be included as a subset of the educational delivery system and even whether there should be internationalization of QA. Arguments are presented for treating open and distance learning, especially e-learning, as requiring special quality assurance procedures and reporting.

- There is an increasing learner-centered focus in e-learning and on student learners as key stakeholders in the QA process; in fact, Jung provides a conceptual framework for learner-oriented QA for e-learning that includes cultural variables for cross-cultural learning situations. This cultural issue is raised elsewhere in the book as it becomes important for today's and tomorrow's technologies that allow educational reach well beyond national borders. (An interesting point is made elsewhere by Lockee, Perkins, Potter, Burton, and Kreb when they recently reviewed 17 national and international organizations' quality standards. They noted different emphasis on standards regarding course design issues and instructor preparation [cited in Irele, in press]).

Currently, quality assurance is a phrase frequently associated with e-learning, perhaps, often as a handy platitude from lack of familiarity with systemic approaches to distance education and lack of awareness of the importance of recognizing the various shareholders of education, which often have been invisible (I dare say even ignored). As suggested throughout the book, the growth and popularity of e-learning, along with the emergence of new "enterprising" organizations into the mix, has drawn attention and resulted in unprecedented demands for accountability. As Sir John Daniel writes in the Foreword, "We face the paradox that while open and distance education is growing rapidly in popularity with students and institutions, thanks in part to online technologies, hostility to it is also growing" (p. xvi). 
And the book's authors point out,

There is little research-based literature to guide policymakers, managers and practitioners in applying Quality Assurance (QA) in education and training to ensure the right balance is found between accountability and autonomy, as well as assuring quality for the time and costs involved.

The book that Jung and Latchem pulled together provides much-needed discussion on just what quality assurance in distance education is. It also provides conceptual organizational models and practical strategies for continually working towards quality improvement and for transparently tracking and documenting outcomes. Most importantly, this book finally brings quality assurance from being a lofty ideal into the realm of practical discussion.

On a personal (and professional) note, I smiled when I first read the title of the final chapter, "Concluding Remarks: Quality Matters." Since 2000, I've been involved with a program called just that: Quality Matters ${ }^{1}$. It began as a small group of distance education practitioners who were affiliated with a state-wide distance learning consortium collaborating to improve the quality of course design for shared e-learning courses. We quickly discovered that we were not the only instructors, designers, and program directors wrestling with trying to find a workable process for applying what the research and best practices were reporting about quality assurance in the design of an online course. While Quality Matters is focused on course design issues, we continue to receive questions about myriad other dimensions of quality assurance for e-learning. Practitioners are obviously searching for information and workable models. This book serves as a reference guide for a systems approach to QA by providing example cases (although many are not focused on e-learning) and including multiple models that can be adapted into discussion on a local level, for example "means of gathering data for QA audits and self-reviews" and "an analytic rubric for judging the achievement of KPIs (key performance indicators) or critical success factors" presented in the final chapter.

Even while building a case for QA standards, the authors conclude with the warning to distance education leaders not to succumb to rote technical application of benchmarks, that we must move from external control (which distance education, especially e-learning is faced with now and for the unforeseeable future) to a culture of quality. They remind us that in our rush to respond to external demands for QA in e-learning we should not give up the culture of innovative solutions to continually improve the quality of learning. Tony Bates reviewed of this book on his Web site ${ }^{2}$ and indicates that a big missing piece is a perspective on traditional campus-based universities and colleges, which have unique issues in establishing QA in their e-learning programs that single-mode or virtual open and distance education institutions do not have. Although I agree, I think this book goes a long way to provide a foundation from the experience of others that can be the basis for creativity in quality assurance. It will be useful for those who need models and strategies right now. 


\section{Notes}

http://www.qmprogram.org/

2http://www.tonybates.ca/2012/02/08/book-review-quality-assurance-in-distance-education-and-e-learning/

\section{Reference}

Irele, M. E. (in press). Evaluating distance education in an era of internationalization. In M. G. Moore (Ed.), Handbook of distance education ( $3^{\text {rd }}$ ed.). Mahwah, N.J.: Lawrence Erlbaum Associates.

\section{Athabasca University $\mathbf{A}$}

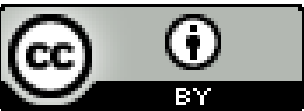

